\title{
DURABILIDADE E DESEMPENHO DOS COMPONENTES DE UM SISTEMA DE PULVERIZAÇÃO ACOPLADO AO PIVÔ CENTRAL ${ }^{1}$
}

\section{DURABILITY EVALUATION OF A PULVERIZATION SYSTEM COMPONENTS, ATTACHED TO CENTRAL PIVOT}

\author{
Robson André ARMINDO ${ }^{2}$ \\ Tarlei Arriel BOTREL ${ }^{3}$ \\ Priscila Rosenbaum FERIANCIC ${ }^{4}$
}

\begin{abstract}
RESUMO
Neste trabalho, teve-se por objetivo avaliar a durabilidade e o desempenho de um protótipo de sistema de pulverização (NOTLIADA), acoplado ao sistema de irrigação pivô central, quanto ao conjunto de emissão; ao conjunto eletro-eletrônico de acionamento; a válvula solenóide; e a adaptação de uma tubulação de cloreto de polivinila (PVC), de instalação predial soldável. Os testes foram realizados em um protótipo do sistema, montando em uma área anexa ao Laboratório de Hidráulica do Departamento de Engenharia Rural (LER), pertencente à Escola Superior de Agricultura "Luiz de Queiroz" - ESALQ/USP. Os resultados obtidos evidenciaram que não houve alteração, a $5 \%$ de significância, da vazão dos quatro tipos de conjuntos de emissão testados em 505 horas intermitentes de avaliação. Também a 5\% de significância, não houve variação dos diâmetros dos emissores. O circuito eletro-eletrônico, a válvula solenóide, a tubulação de material PVC (cloreto de polivinila) soldável e os demais dispositivos da barra de pulverização operaram satisfatoriamente no mesmo período de avaliação confirmando a confiabilidade do sistema de pulverização desenvolvido.
\end{abstract}

Palavras-chave: Emissores; Válvula Solenóide; Automação; Notliada.

\begin{abstract}
This work aimed to evaluate the durability and performance of the pulverization system prototype (NOTLIADA) attached to center pivot irrigation system. The flow emission sets, electronic actuation, solenoid valve and the adaptation of a polyvinyl chloride (PVC) pipe were evaluated. Tests were performed on a prototype system, riding in the Laboratório de Hidráulica of the Departamento de Engenharia de Biossistemas belonging to the Escola Superior de Agricultura "Luiz de Queiroz" - ESALQ /USP. The results showed no change, $5 \%$ significance level, in the flow of the four different emission sets tested in intermittent evaluation and also, no significant variation of the emitters diameters. The circuit electronics, solenoid valve, pipe and other devices of the spray bar operated satisfactorily during the same period of evaluation confirmed the reliability of the pulverization system developed.
\end{abstract}

Key-words: Emitters, Solenoid Valve; Automation; Notliada

\footnotetext{
${ }^{1}$ Parte da Dissertação de Mestrado do primeiro autor apresentada ao curso de pós-graduação em Irrigação e Drenagem da Universidade de São Paulo.

${ }^{2}$ Prof. Dr. Departamento de Solos e Engenharia Agrícola, Universidade Federal do Paraná, Rua dos Funcionários, 1540 - Bairro Juvevê, CEP. 80.035-050, Curitiba, PR, Brazil. E-mail: rarmindo@ufpr.br. Autor para correspondência.

${ }^{3}$ Departamento de Engenharia de Biossistemas, Universidade de São Paulo, Piracicaba, SP, Brazil. E-mail: tabotrel@esalq.usp.br

${ }^{4}$ Agrônoma, Universidade de São Paulo, Piracicaba, SP, Brazil. E-mail: priscilarosenbaum@hotmail.com
} 
ARMINDO, R.A.. et al. Durabilidade e desempenho...

\section{INTRODUÇÃO}

$\mathrm{Na}$ agricultura, o ataque de pragas e a manifestação de doenças implicam em parcial ou total comprometimento da produção das culturas. Para que não ocorra perda na produção, uma das formas que o agricultor dispõe se refere a utilização de sistemas de pulverização no combate a essas pragas e doenças. Em razão disso, a pulverização de defensivos agrícolas objetiva principalmente a aplicação da dosagem correta do defensivo no alvo desejado. Diversos sistemas de pulverização como costais, sistemas acoplados a tratores, a aviões, a pivôs centrais e a sistemas lineares de irrigação são utilizados para a aplicação de herbicidas, fungicidas, inseticidas e fertilizantes. Contudo, a viabilidade técnica, econômica e ambiental para a utilização desses sistemas é contestável principalmente para a agricultura irrigada.

Aplicações de produtos químicos com a utilização de pulverizadores costais, manuais e motorizados de pequeno portesão tecnicamente inviáveis em grandes áreas. O tráfego de tratores na área geralmente depende de boas condições meteorológicas, umidade adequada do solo e cultura em baixo porte. O deslocamento do conjunto pulverizador pode provocar danos às plantas deixando assim de ser viável tecnicamente. A contaminação do operador é outro fator preocupante nesse tipo de operação (Vilela et al, 2004).

A aplicação por aeronaves só é recomendada em condições ideais de umidade relativa, temperatura e velocidade do vento, além da inexistência de neblina. Outros fatores como a impossibilidade de aplicação noturna, chuva, pista de aterrissagem, abastecimento, necessidade de mão-de-obra auxiliar, distância do translado, situação topográfica local, custo elevado (comparado aos demais sistemas) e possibilidade de contaminação, tanto de auxiliares quanto do ambiente, apresentam-se como desvantagem desse tipo de aplicação.

Dessa forma, a introdução de alta tecnologia em aplicação de defensivos na agricultura irrigada justifica-se, visto que os efeitosdos defensivos agrícolas são grandemente influenciados pelos métodos e épocade aplicação, pelas recomendações da operação e exatidão do equipamento utilizado.

Os sistemas de pulverização acoplados aos pivôs centrais geralmente são constituídos de equipamentos independentes dos mecanismos de distribuição de água (Vilela et al., 2004 e Summer et al., 1997). São sistemasque atingem menores lâminas de aplicação e diâmetros de gotas, além de maior eficiência de aplicação. Vilela et. al (2004) comentam que o sistema intermitente de pulverização acoplado ao pivô central, Notliada, pode efetuar a quimigação com calda de $286 \mathrm{~L}^{\text {ha }}{ }^{-1}$ de aplicação e diâmetro médio volumétrico (DMV) de 126,30 $\mu \mathrm{m}$; com satisfatória uniformidade de aplicação, classificada de acordo com Cupery (1987).

Para atingir calda reduzida, os sistemas de pulverização acoplados aos pivôs centrais utilizam tecnologia modular de acionamento de válvulas solenóides, semelhante a utilizada em sistemas de pulverização acoplados em tratores. As válvulas solenóides são inseridas na entrada da barra de pulverização alterando o fluxo e proporcionando alteração da vazão dos bicos emissores inseridos na barra (Omary et al., 1997 e Farahani et al., 2006). Porém, as válvulas solenódeis podem ser inseridas individualmente em cada bico emissor, controlando-se sua vazão individual (King \& Kincaid, 2005 e Armindo et al., 2010). A realização de calibração para a utilização desses sistemas tornase necessária, pois os erros entre as vazões estimadas e observadas, existentes na calibração em uma pulverização podem se originar do uso de bicos (impróprios, defeituosos ou desgastados), da velocidade de deslocamento da máquina utilizada ou na determinação das vazões. Esses erros podem ocasionar caldas mais concentradas que, consequentemente, serão mais prejudiciais ao meio ambiente, além de possuírem maiores custos.

Armindo et al. (2009) modelando, por análise de regressão, a predição de vazão do sistema Notliada concluíram que o erro entre as vazões estimada e observada aumentou exponencialmente quando se aumentou a freqüência de operação da válvula solenóide para se obter menores lâminas de aplicação. Os autores mostraram ainda que, o erro na aplicação pode ser da ordem de $80 \%$ em relação ao volume de aplicação dimensionado para altas freqüências de operação da válvula solenóide. Essas variações ocorridas podem ser explicadas por diversas causas, tais como: ineficiência do circuito eletro-eletrônico de acionamento da válvula solenóide, que pode ocasionar tempo de resposta hidráulico insuficiente para pressurização dos conjuntos de emissão; desgaste dos conjuntos de emissão, devido a sobrepressão atuante, ocasionada pelo acionamento das solenóides, entre outras.

Neste trabalho, teve-se por objetivo avaliar a durabilidade e o desempenho de um protótipo do sistema de pulverização, Notliada, acoplado ao sistema pivô-central quanto ao conjunto de emissão; ao dispositivo eletro-eletrônico de acionamento; a válvula solenóide; e a adaptação de uma tubulação de cloreto de polivinila (PVC), de instalação predial soldável.

\section{MATERIAL E MÉTODOS}

\section{Localização e Etapas do Experimento}

$O$ desenvolvimento do trabalho foi realizado no Departamento de Engenharia Rural da Escola Superior de Agricultura "Luiz de Queiroz" (ESALQ), da Universidade de São Paulo (USP), no município de Piracicaba - SP. A construção do equipamento de pulverização utilizado foi baseada no sistema Notliada, apresentado por Vilela et al. (2004). O teste do protótipo foi realizado sobre suportes fixos, em que o sistema de pulverização ficou instalado e permaneceu estático, já que para o objetivo desse trabalho o sistema não necessitou ser dinâmico.Todas as avaliações foram feitas com água pura como recomendado pela norma ISO9260:1991(E) (International Standart Organization, 1991).

O sistema hidráulico foi composto das seguintes partes: conjunto de emissão, formado por 
ARMINDO, R.A.. et al. Durabilidade e desempenho...

emissores, dispositivos antidrenantes e conectores; barra de pulverização; válvula solenóide; regulador de pressão; tubulações de alimentação; conjunto moto-bomba; reservatório; registros; sistemas de filtragem, dentre outros. Algumas partes foram formadas pela associação de outros elementos, (Figura 1-b). O sistema eletro-eletrônico foi composto das seguintes partes: microcontrolador, fonte de alimentação, relê, transistor, resistores, entre outros (Figura 2).

\section{Conjunto de emissão}

Constituiu-se de noventa bicos emissores do tipo Fogger 7800, que possuem diâmetros codificados por cores, fabricado pela empresa israelense Dan Sprinklers. Para de maior precisão, realizou-se a determinação dos diâmetros médios dos bocais de todos emissores, valendo-se do projetor de perfil modelo HB 400, fabricado pela empresa Starret (Figura 1).

A
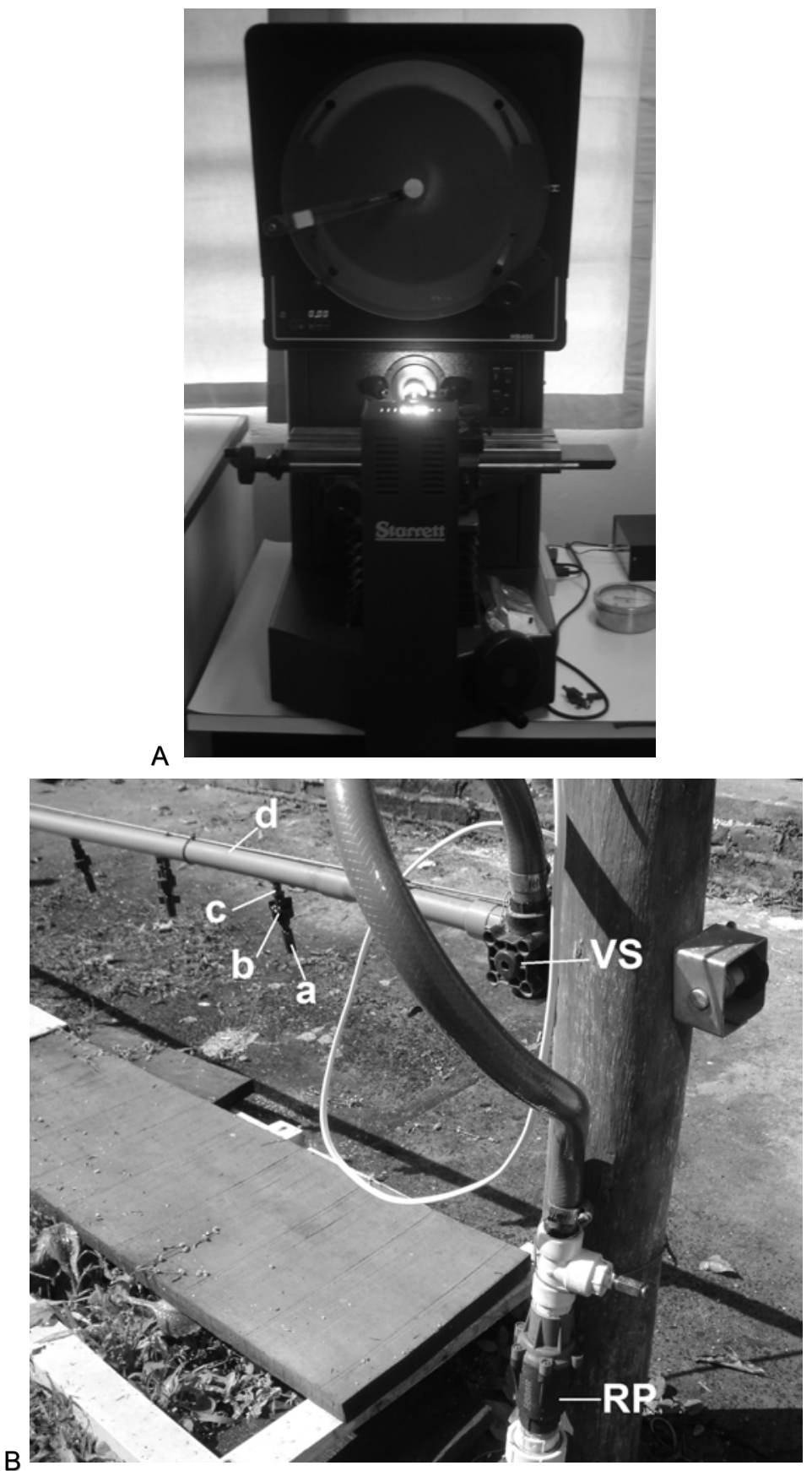

Figura 1 - Projetor de perfil utilizado com detalhes na determinação do diâmetro de um emissor $(A)$ e barra de pulverização construída (B) de tubulação soldável (d) com válvula solenóide utilizada na entrada da barra (VS), regulador de pressão (RP) e conjunto emissor dividido em: conector (a), dispositivo antidrenante (b), emissor (c). 
ARMINDO, R.A.. et al. Durabilidade e desempenho...

\begin{abstract}
Noventa válvulas antidrenates (antidrenantes) Leakage Prevention Device (LPD) modelo "baixa pressão", codificadas pelo fabricante pela cor preta, produzidas pelo mesmo fabricante dos emissores foram utilizadas para evitar a formação de gotas nas extremidades externas dos bocais e para manter a barra de pulverização totalmente preenchida com líquido nos momentos em que a pulverização não estivesse ocorrendo. As pressões de fechamento e abertura das válvulas são de 70 e $200 \mathrm{kPa}$, respectivamente. A conexão do conjunto formado pelos emissores e válvulas antidrenantes à barra de pulverização foi efetuada por meio de noventa conectores específicos para essa finalidade, denominados butterfly treaded, também produzidos pelos mesmos fabricantes dos emissores e válvulas antidrenantes.
\end{abstract}

As curvas vazão versus pressão dos noventa conjuntos de emissão (divididos em quatro codificações de cores) foram determinadas, baseando-se na norma ISO9260:1991(E) International Standart Organization, (1991), utilizando-se pressões no sistema de $205,255,275,295,315,335$, $355,375,395,415$ e $435 \mathrm{kPa}$. Para cada ponto de pressão foram realizadas três coletas de vazão por conjunto de emissão, determinando-se a vazão média de cada conjunto, totalizando 1485 coletas de vazão. As vazões foram determinadas pelo método gravimétrico considerando-se a massa específica da água igual a $1 \mathrm{~g} \mathrm{~cm}^{-3}$.

Na sequência, o sistema entrou em operação por um período de 505 horas, de forma intermitente com a frequência de operação da válvula solenóide em tempo ligado $\left({ }^{t_{1}}\right.$ ) de 0,9 s e tempo desligado $\left({ }^{t d}\right)$ de $2,5 \mathrm{~s}$, que se referem à freqüência mais crítica de operação do sistema (Armindo et. al, 2009). Com a utilização de um regulador de pressão antecipadamente a válvula solenóide, regulouse a pressão sobre os noventa conjuntos de emissão em $245 \mathrm{kPa}$, sendo essa a pressão de serviço para os quatro conjuntos de emissão utilizados, que são codificados pelo fabricante nas cores preto, vermelho, laranja e azul. Após as 505 horas, realizou-se novamente a determinação dos diâmetros médios dos bocais dos noventa conjuntos de emissão testados, além de um novo ensaio de vazão para posterior análise dos resultados. A análise estatística desses resultados foi realizada por meio de uma regressão linear e teste "t" com nível de significância de $5 \%$.

\section{Barra de Pulverização}

O conjunto de emissão foi preparado e instalado em uma tubulação de PVC rígido, soldável, de cor marrom e com diâmetro de $25 \mathrm{~mm}$ (3/4"). A barra de pulverização foi montada a uma altura de $50 \mathrm{~cm}$ do solo adaptando-se uma tomada de carga no início e outra no final da tubulação, a fim de se determinar a perda de pressão ao longo da barra durante o funcionamento do sistema (Figura 2). A fim de verificar se a tubulação recomendada para projetos do Notliada pode ser substituída pela tubulação em estudo, avaliou-se a durabilidade da tubulação utilizada no sistema por um período de 505 horas, com funcionamento intermitente da válvula solenóide.

\section{Válvula solenóide}

A válvula solenóide ficou instalada na entrada da barra de pulverizaçãopara controlar o fluxo hidráulico proveniente da tubulação de alimentação para a barra e produzir um efeito de intermitência do sistema de pulverização (Figura 3).

Utilizou-se a válvula do modelo AA144A-1, fabricada pela empresa Spray Systems e usualmente empregada em pulverizadores agrícolas. Essa válvula é do tipo "normalmente fechada" e quando submetida a diferença de potencial elétrico de +12 Vcc e corrente de 2,5 A, abrem-se quase que instantaneamente, permitindo a passagem do líquido por sua câmara interna.

\section{Circuito eletro-eletrônico}

O efeito de intermitência do sistema Notliada dependeu da ação do circuito eletro-eletrônico e da válvula solenóide. Esse circuito foi comandado por um algoritmo desenvolvido e compilado em um microcontrolador, responsável pelas diversas freqüências de acionamento impostas à válvula solenóide (Figura 2).

O acionamento do pino do microcontrolador referente à frequência escolhida excitava a base do transistor que automaticamente acionava um relê. Esse dispositivo eletro-mecânico exerce um regime de trabalho semelhante a uma chave, permitindo ou não o fluxo de energia elétrica responsável pela alimentação da válvula solenóide.

Alimentou-se o circuito eletro-eletrônico com uma tensão de $12 \mathrm{Vcc}$, fornecida por uma fonte projetada exclusivamente para esse fim. A válvula solenóide necessitou de um maior valor de corrente elétrica e foi alimentada com uma bateria de $12 \mathrm{Vcc}$, capaz de fornecer a carga demandada.

\section{Efeito intermitente do protótipo NOTLIADA}

A pulverização em taxa variada no sistema Notliada foi obtida com a intermitência da válvula solenóide, instalada na entrada da barra de pulverização. O sistema foi programado para funcionar alternando tempos de $0,9 \mathrm{~s}$ de ligamento e $2,5 \mathrm{~s}$ de desligamento. $\mathrm{O}$ acionamento da válvula solenóide segue um comportamento de uma função degrau do tipo Oliver Heaviside (Figura 3). 
A

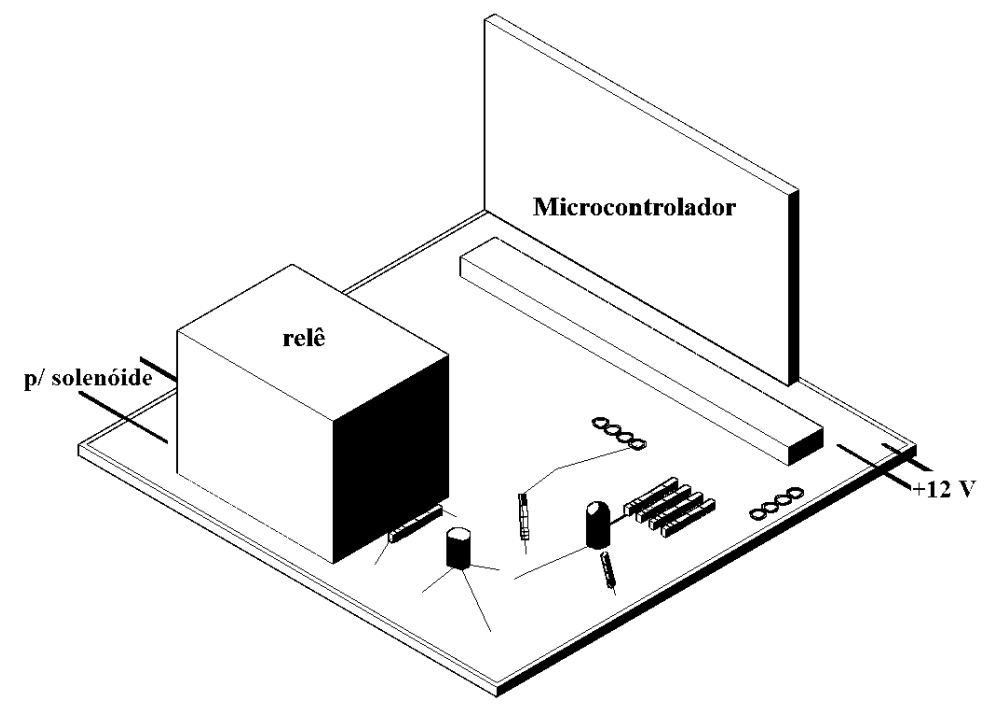

$B$

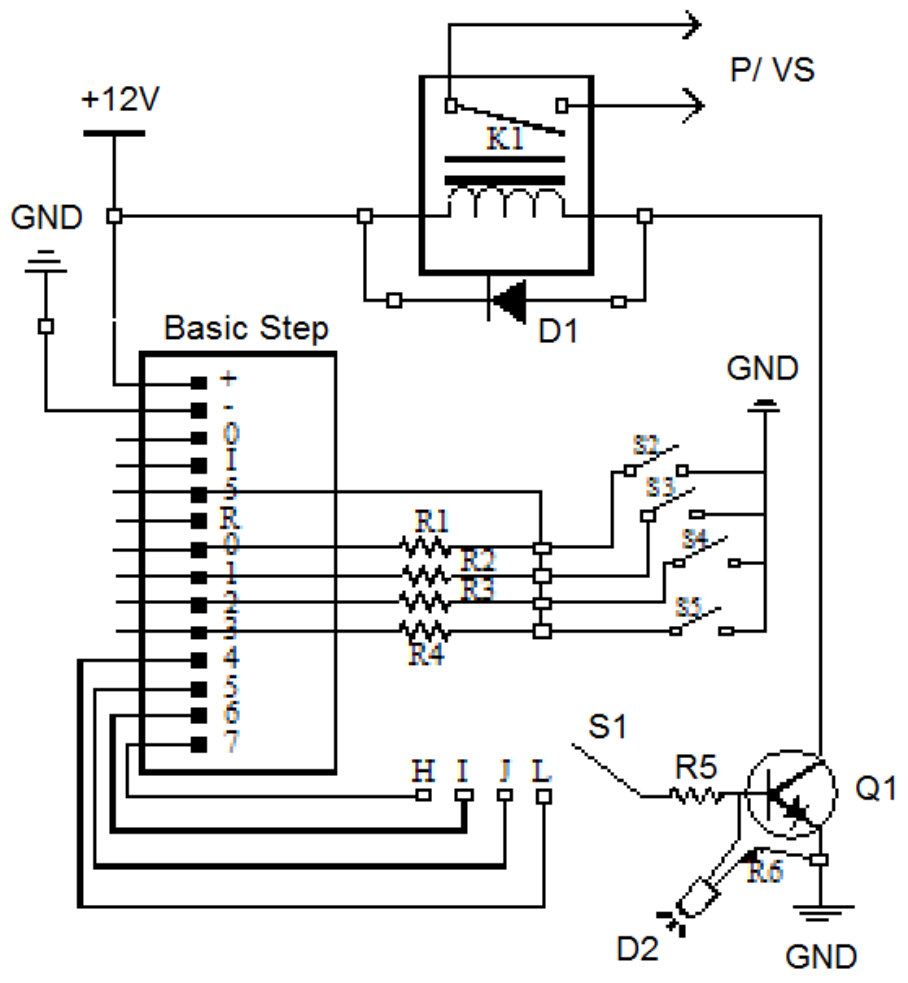

Figura 2 - Imagem (A) e esquema (B) do circuito eletro-eletrônico microcontrolado.

D1 e D2: Diodos 007 e LED

0 a 7: Pinos do Basic Step

K1: relê A1RC2 12Vcc

Q1: Transistor

BC 548B

$\mathrm{H}, \mathrm{I}$, J e L: Posições

VS: Válvula Solenóide

R1 a R6: Resistores 
ARMINDO, R.A.. et al. Durabilidade e desempenho...

Parametrizando-se a função que descreve a pressão atuante no sistema Notliada em função do tempo, encontra-se a eq. (1).

$$
\mathrm{H}(\mathrm{t})=\mathrm{Hs}-\mathrm{Hs} \times \mathrm{u}\left(\mathrm{t}-\mathrm{t}_{1}\right)+\mathrm{Hs} \times \mathrm{u}\left(\mathrm{t}-\mathrm{t}_{2}\right)+\ldots
$$

Em que:

$$
\mathrm{t}_{1}=\mathrm{t}_{1}-\mathrm{t}_{0} \quad \mathrm{td}=\mathrm{t}_{2}-\mathrm{t}_{1}
$$

$\mathrm{t}_{1}$

: tempo em que a válvula solenóide permanece ligada, T;

td : tempo em que a válvula solenóide permanece desligada, T;

$t_{0}$ : tempo instantâneo que se liga a válvula solenóide, T;

$\mathrm{t}_{1}$ : tempo instantâneo que se desliga a válvula solenóide, $\mathrm{T}$;

$\mathrm{t}_{2}$ : tempo instantâneo que se liga a válvula solenóide, $\mathrm{T}$; $\mathrm{H}(\mathrm{t})$ : pressão em qualquer instante de tempo t, $\mathrm{F} \mathrm{L}^{-2}$;

Hs : pressão de serviço, $\mathrm{F} \mathrm{L}^{-2}$;

$\mathrm{T}$ : período, $\mathrm{T}$.

O sistema foi pressurizado no intervalo $\left({ }^{t_{1}}\right.$ ) aplicando-se o volume programado, originado da frequência crítica de operação da válvula solenóide. O intervalo de tempo desligado ( ${ }^{\text {td }}$ ) é responsável pelo efeito de redução da calda. Entretanto, em $\left({ }^{t_{1}}\right)$ existe um golpe de sobrepressão, ocasionado pelo acionamento da válvula solenóide, que ultrapassa a pressão de serviço (Hs) e que pode comprometer os conjuntos de emissão, bem como a tubulação.

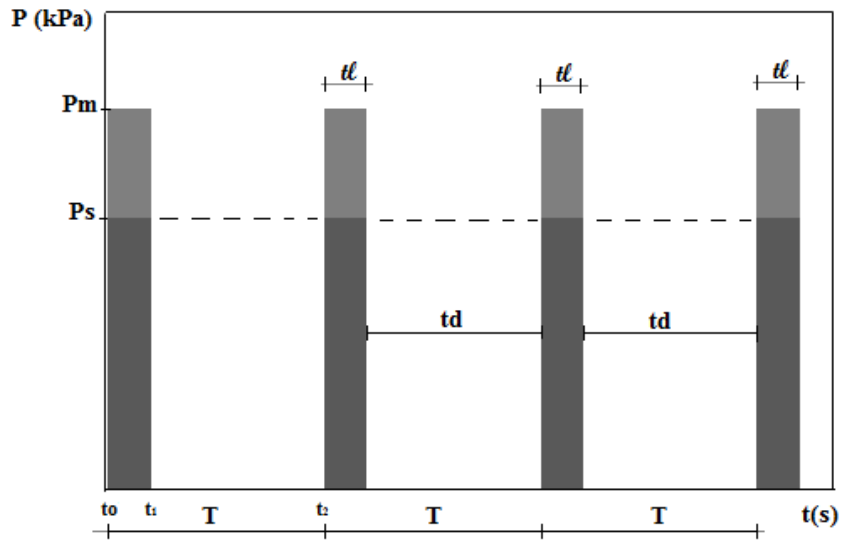

Figura 3 - Representação do funcionamento da válvula solenóide no tempo em função degrau. Tempo ligada $(\mathrm{tl})$, tempo desligada $(\mathrm{td})$, liga solenóide $\left(\mathrm{t}_{0}\right)$, desliga solenóide $\left(\mathrm{t}_{1^{-}}\right)$, liga solenóide $\left(\mathrm{t}_{2}\right)$, pressão de serviço $(\mathrm{Hs})$ e período $(\mathrm{T})$.

\section{Descrição geral do funcionamento do sistema hidráulico}

A água utilizada nos testes foi pressurizada com um conjunto moto-bomba e conduzida nas tubulações de alimentação até a entrada do regulador de pressão, sendo transportada a partir desse ponto por uma tubulação flexível até a válvula solenóide. Posicionou-se a válvula solenóide no início da barra de pulverização para permitir ou bloquear o fluxo de água, propiciando a intermitência do sistema.
A barra de pulverização esteve totalmente preenchida. Devido à ação estanque das válvulas antidrenantes, possibilitando a operação dos noventa conjuntos de emissão quase instantaneamente à abertura da válvula solenóide. A fim de se evitar o entupimento dos emissores e/ou seus desgastes, por abrasão de partículas que se encontram em suspensão na água, utilizou-se um filtro de tela de 120 mesh para efetuar a filtragem da água, que foi conduzida a barra de pulverização. Ademais, por meio de registro de gaveta na extremidade final da tubulação, eliminou-se o risco de sedimentação de partículas na barra de pulverização. 
ARMINDO, R.A.. et al. Durabilidade e desempenho...

TABELA 1 - Parâmetros " $k$ " e " $x$ " de ajuste das curvas potenciais de pressão versus vazão para os quatros conjuntos de emissão avaliados com o coeficiente de variação de "k" (CVk), coeficiente de variação de " $x$ " (CVx), coeficiente de determinação $\left(R^{2}\right)$ e soma dos quadrados (SQ).

\begin{tabular}{cccccccc}
\hline & \multicolumn{5}{c}{ Parâmetros } \\
\hline conjuntos de emissão & $\mathrm{K}$ & $\mathrm{CVk}(\%)$ & $\mathrm{x}$ & $\mathrm{CVx}(\%)$ & $\mathrm{R}^{2}$ & $\mathrm{SQ}$ & Valor de "F" $^{\text {(\%) }}$ \\
\hline Preto & 10,6608 & 2,0020 & 0,5741 & 2,8020 & 0,9935 & 0,4644 & $1374,1383^{*}$ \\
Vermelho & 8,3943 & 1,8790 & 0,551 & 2,7650 & 0,9921 & 0,2456 & $1407,1762^{*}$ \\
Laranja & 5,8463 & 1,7390 & 0,5534 & 2,5290 & 0,9947 & 0,1011 & $1688,7235^{*}$ \\
Azul & 2,8221 & 1,9050 & 0,5837 & 2,6210 & 0,9942 & 0,0300 & $1580,1462^{*}$ \\
\hline
\end{tabular}

* Significativamente diferente $(P<0,0001)$

\section{RESULTADOS E DISCUSSÃO}

\section{Determinação da curva vazão versus pressão}

Realizou-se, por anamorfose, o ajuste de regressão das curvas vazão versus pressão para os quatro tipos de conjuntos de emissão codificados nas cores: preto, laranja, azul e vermelho (Figura 4). Os ajustes permitiram a determinação dos parâmetros de regressão "k" e " $x$ " das quatro equações (Tabela 1).

\section{Durabilidade dos emissores}

Verificou-se que os diâmetros dos emissores após 505 horas de funcionamento $\left(D_{505}\right)$ apresentaram maiores valores que os diâmetros medidos antes do funcionamento $\left(D_{0}\right)$. Os resultados obtidos servem como indicadores de desgaste que proporcionam em aumento de vazão. Entretanto, os diâmetros de $D_{505}$, que apresentaram menores valores que $D_{0}$, evidenciaram uma redução desse diâmetro, devido a entupimentos que ocasionaram redução da vazão.

Antes e depois do tempo de ensaio adotado (505 h) não houve diferença significativa entre os valores de vazão testados (Figura 5-a) evidenciando que nenhum dos quatro conjuntos de emissão utilizados no processo sofreu entupimento ou corrosão.

Não houve diferença significativa entre os valores de diâmetros dos conjuntos de emissão testados (Figura 5-b), evidenciando que não houve entupimento ou corrosão garantindo a durabilidade dos conjuntos de emissão utilizados no tempo testado.

Em ambas as retas de comparação apresentadas (Figura 5), percebe-se que o coeficiente linear tende ao valor zero, enquanto o coeficiente angular tende ao valor unitário. Dessa forma, aceita -se que as duas variáveis testadas tendem ao mesmo valor, ou seja, não existe diferença entre elas.

\section{Durabilidade do dispositivo eletro-eletrônico}

Como o sistema de pulverização NOTLIADA é composto de extenso material havia dúvida quanto sua durabilidade, principalmente quanto aos dispositivos eletro-eletrônicos utilizados. As substâncias químicas que compõem os componentes eletrônicos se deterioram e perdem suas propriedades com o passar do tempo, o que é absolutamente normal. Entretanto, é difícil saber com exatidão quanto um componente pode durar. $\mathrm{Na}$ prática, estipula-se que esses componentes durem em média entre dois e quatro anos.

No NOTLIADA, o microcontrolador, o relê, o transistor e demais componentes eletroeletrônicos utilizados no circuito desenvolvido não apresentaram falhas de funcionamento durante todo tempo dos ensaios de vazão realizados e, principalmente, durante todo o período interrupto de 505 horas de funcionamento da barra de pulverização. O ideal seria testar o sistema de pulverização durante o número de horas necessárias para que os componentes eletro-eletrônicos apresentassem falha. Contudo, haveria a necessidade de repetir o ensaio, no mínimo três vezes, garantindo que nessas repetições haveria sempre a falha do mesmo componente eletro-eletrônico; seja um transistor, um relê, um resistor ou, até mesmo, o microcontrolador. Dessa forma, esse período de observação passaria a ser tecnicamente inviável.

\section{Utilização de tubulação PVC soldável}

A tubulação de material PVC soldável de diâmetro de 19,05 mm (3/4") não apresentou vazamentos nas junções entre os conectores e a barra durante todos os ensaios. Com o auxílio de cabos de aço para sua fixação e sustentação, a barra de pulverização não apresentou catenárias que alterassem sua estrutura mantendo-se em nível durante toda a experimentação. Dessa forma, a tubulação soldável pode ser recomendada para o sistema de pulverização NOTLIADA, uma vez que a tubulação roscável utilizada por Vilela et al. (2004) apresenta maior custo fixo no mercado. 
ARMINDO, R.A.. et al. Durabilidade e desempenho...

A

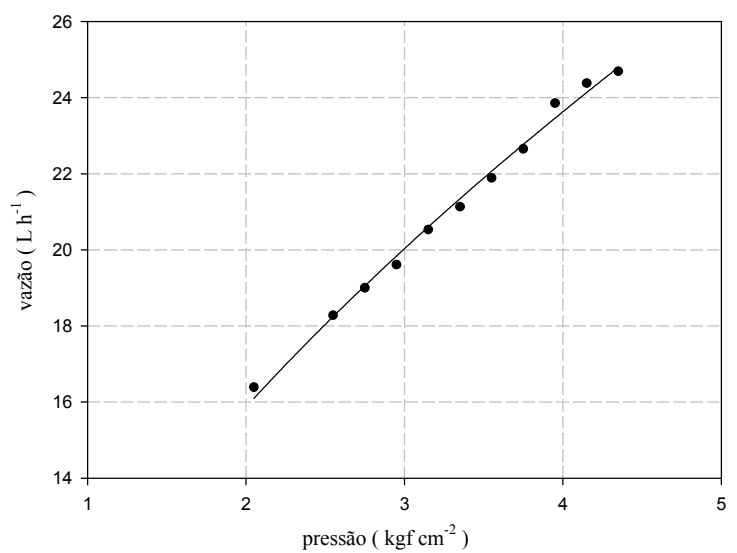

C

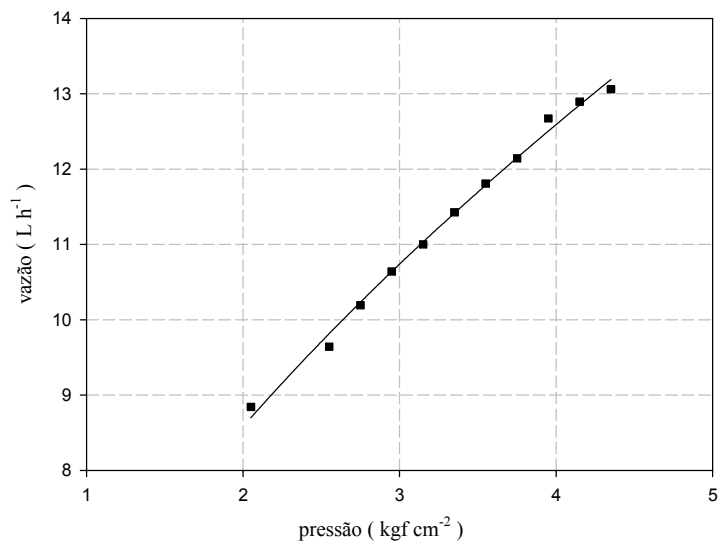

B

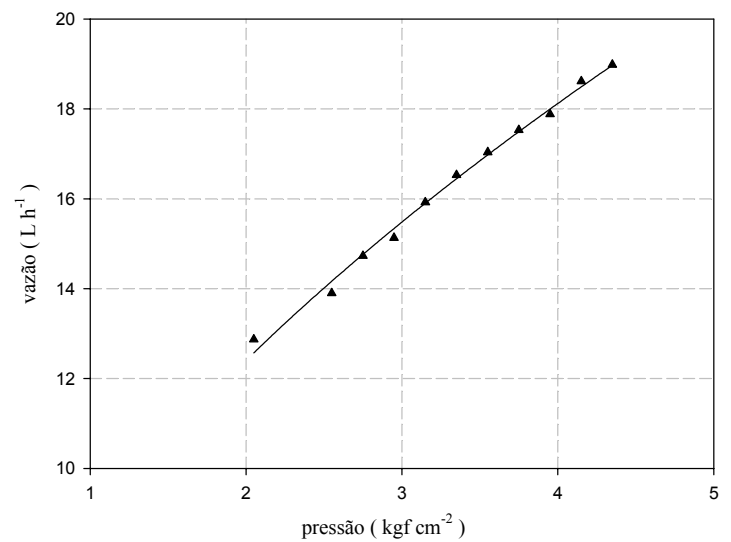

D

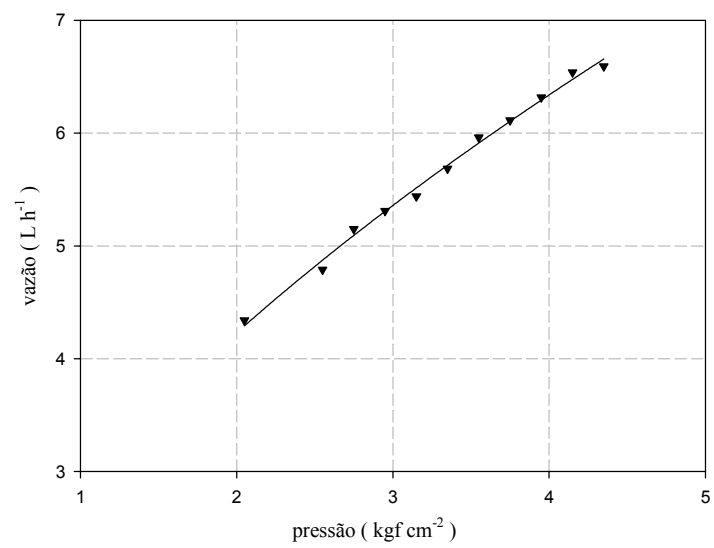

Figura 4 - Curvas potenciais de vazão versus pressão ajustadas para os conjuntos de emissão avaliados codificados pelo fabricante nas cores preto $(A)$, vermelho $(B)$, laranja (C) e azul (D).

A

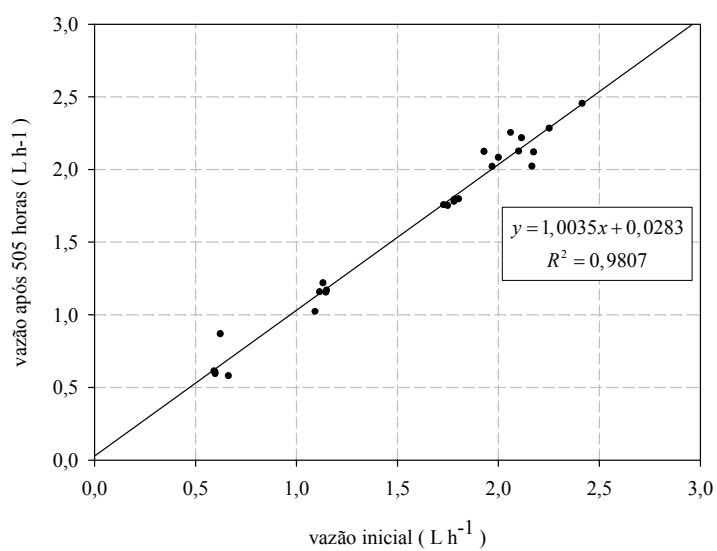

B

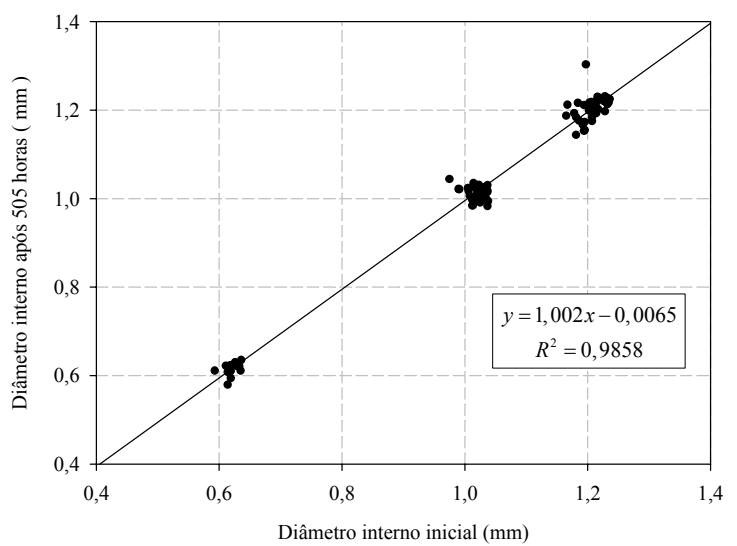

Figura 5 - Retas 1:1 de comparação das vazões observadas, antes e após 505 horas de funcionamento (A) e dos diâmetros medidos, antes e após 505 horas de funcionamento (B). 
ARMINDO, R.A.. et al. Durabilidade e desempenho...

\section{Durabilidade e estanqueidade da válvula sole- nóide}

A válvula solenóide manteve-se estanque mesmo após o período de testes em que foi submetida apresentando confiabilidade em seu uso. A frequência utilizada de $0,9 \mathrm{~s}$ de ligamento por 2,5 $\mathrm{s}$ de desligamento da válvula solenóide corresponde a um número aproximado de 20 atuações por minuto. Sendo assim, em 505 h de funcionamento, a válvula solenóide atuou aproximadamente 586.450 vezes sem apresentar problemas de vazamento entre sua saída e a entrada da tubulação. Considerando-se que as atividades de pulverização acontecem algumas vezes durante uma safra, notase que o sistema NOTLIADA pode ser utilizado por muitas safras sem apresentar problemas quanto a válvula solenóide.

\section{CONCLUSÕES}

A partir dos resultados do estudo, nas condições de avaliação do trabalho, conclui-se que: i) os quatro tipos de emissores testados possuem durabilidade satisfatória. Todos conectores e válvulas antidrenantes também apresentaram durabilidade satisfatória. ii) $O$ conjunto eletro-eletrônico não apresentou nenhuma falha proporcionando desempenho estável em todo período de acionamento da válvula solenóide. iii) A válvula solenóide permaneceu estanque após o período de intermitência em que foi submetida. iv) Não foi identificada nenhuma alteração do sistema, Notliada, utilizando-se tubulação de material PVC soldável.

\section{AGRADECIMENTOS}

Os autores agradecem ao Ministério da Ciência e Tecnologia (MCT), ao Conselho Nacional de Desenvolvimento Científico e Tecnológico $(\mathrm{CNPq})$ e à Fundação de Amparo à Pesquisa do Estado de São Paulo (FAPESP), pelo apoio financeiro a esta pesquisa, através do Instituto Nacional de Ciência e Tecnologia em Engenharia da Irrigação (INCTEI).

\section{REFERÊNCIAS}

1. ARMINDO, R.A. et al. Avaliação do sistema de pulverização com funcionamento intermitente, acoplado ao pivô central, Notliada. Revista Brasileira de Engenharia Agrícola e Ambiental, v.13, n.1, p. 26-32, 2009.

2. ARMINDO, R.A. et al. Flow rate sprinkler development for site-specific irrigation. Irrigation Science, v. 29, n.3, p. 233240, 2010.

3. AMERICAN SOCIETY OF AGRICULTURAL ENGINEERS. Terminology and definitions for agricultural chemical applications. ASAE Standards, v.1, p.159-161, 1996.

4. CUPERY, E.W. Application accuracy. West Clark: Methods of applying herbicides, 1987. p.63-84. (eds).

5. FARAHANI, H.J. et al. Evaluation of a low volume agro-chemical application system for center pivot irrigation. Transactions of the ASABE, v. 22, p. 517-528, 2006.

6. INTERNATIONAL STANDART ORGANIZATION. Agricultural irrigation equipment - emitters - specification and test methods - ISO 9260:1991 (E). Genève: 1991. 7p

7. KING, B.A.; KINCAID D.C. A variable flow rate sprinkler for site-specific irrigation management. Transactions of the ASAE, v. 20, p. 765-770, 2005.

8. OMARY, M. et al. Center pivot irrigation system modification to provide variable water application depths. Applied Engineering in Agriculture, v.13, n.2, p. 235-239, 1997.

9. SUMMER, H.R. et al. Chandler, L.D. Center pivot irrigation attached sprayer. Applied Engineering in Agriculture, v.13, n.3, p.323-327, 1997.

10. VILELA, L.A. et al. Desenvolvimento de um sistema de pulverização acoplável a pivô central. Revista Brasileira de Engenharia Agrícola e Ambiental, v.8, n.2/3, p.311-315, 2004

Recebido em 13/01/2010

Aceito em 12/07/2011 